\title{
Pulse Therapy With Corticosteroids and Intravenous Immunoglobulin in the Management of Severe Tocilizumab-Resistant COVID-19: A Report of Three Clinical Cases
}

Mikhail V. Sheianov ${ }^{1}$, Yurii D. Udalov ${ }^{2}$, Sergei S. Ochkin ${ }^{3}$ Andrei N. Bashkov 4 , Aleksandr S. Samoilov 2

1. Department of Pulmonology, Burnasyan Federal Medical Biophysical Center of Federal Medical Biological Agency of Russia, Moscow, RUS 2. Management, Burnasyan Federal Medical Biophysical Center of Federal Medical Biological Agency of Russia, Moscow, RUS 3. Department of Anesthesiology and Critical Care, Burnasyan Federal Medical Biophysical Center of Federal Medical Biological Agency of Russia, Moscow, RUS 4. Department of Radiology, Burnasyan Federal Medical Biophysical Center of Federal Medical Biological Agency of Russia, Moscow, RUS

Corresponding author: Mikhail V. Sheianov, msheyanov@mail.ru

\begin{abstract}
We present the cases of three patients with severe, life-threatening coronavirus disease 2019 (COVID19) who had failed to achieve substantial improvement on intial treatment. They subsequently received pulse therapy with methylprednisolone [1,000 $\mathrm{mg} /$ day intravenously (IV) for three consecutive days] and IV immunoglobulin ( $20 \mathrm{~g} /$ day). This treatment regimen was associated with a prompt resolution of respiratory failure, elimination of clinical manifestations of the cytokine release syndrome (CRS), and reversal of pulmonary CT changes. The treatment was generally safe and well-tolerated. There was no evidence of protracted persistence of the virus in the patients. Further randomized controlled trials are required to better understand the efficacy and safety of high-dose methylprednisolone and IV immunoglobulin, separately or in combination with each other, in the treatment of severe, life-threatening COVID-19.
\end{abstract}

Categories: Emergency Medicine, Infectious Disease, Pulmonology

Keywords: sars-cov-2, covid-19, pulse therapy, methylprednisolone, immunoglobulin, corticosteroids, cytokine release syndrome

\section{Introduction}

Clinical presentations of coronavirus disease 2019 (COVID-19) range from asymptomatic cases and mildly symptomatic flu-like forms (81\%) to severe (14\%) and critical (5\%) disease manifesting with pneumonia, hepatic, cardiac, and other organ involvement [1]. Respiratory failure and acute respiratory distress syndrome (ARDS) are common complications [2]. Multiorgan failure and disseminated intravascular coagulation (DIC) can also be observed [2,3]. The aforementioned problems determine the need for intensive care in $17-20 \%$ of hospitalized patients [4]. The main cause of death in infected patients worldwide is a combination of both ARDS and DIC leading to a fatal outcome in 11-15\% of hospitalized patients $[4,5]$. The average COVID-19-associated mortality rate has reached $3.7 \%$ of reported cases globally [4].

Received 06/07/2020 Review ended 06/30/2020 Published 07/07/2020

\section{() Copyright 2020}

Sheianov et al. This is an open access article distributed under the terms of the Creative Commons Attribution License CC-BY 4.0., which permits unrestricted use, distribution, and reproduction in any medium, provided the original author and source are credited.
There is growing evidence that the severe course and threatening complications of COVID-19 are caused by excessive and aberrant host immune response induced by the virus in predisposed persons $[5,6]$. In this context, it seems reasonable to consider treatment involving immunosuppressive drugs [glucocorticoids, intravenous (IV) immunoglobulin, and/or anti-cytokine agents] for patients with severe COVID-19 who exhibit cytokine release syndrome (CRS). The obvious aim of such a treatment is to prevent or reverse the dramatic inflammatory pathway triggered by the virus.

Recently, a number of publications have indicated the positive role that specific interleukin-1 (IL-1) and interleukin-6 (IL-6) inhibitors (anakinra, tocilizumab) can play in the treatment of severe COVID-19 complicated with respiratory failure [7-9]. However, there exists a number of COVID-19 patients in whom it is not possible to achieve a sustained improvement with the use of these drugs [9]. Moreover, tocilizumab and other IL blockers belong to a group of relatively expensive drugs, and this may hamper their use in wide-scale epidemics or in less prosperous healthcare systems. These issues have motivated us to look for alternative options for the treatment of severe, life-threatening cases of COVID-19.

In this report, we describe three cases of severe COVID-19 successfully treated with a combination of methylprednisolone pulse therapy and IV immunoglobulin.

\section{Case Presentation}

\section{Case 1}




\section{Cureus}

A 64-year-old woman with obesity and a history of moderately severe asthma fully controlled on medication presented on April 6, 2020, with six days of fever of up to $38.8^{\circ} \mathrm{C}$, dry exhausting cough, and shortness of breath with little exercise. On examination, she was normothermic $\left(36.2^{\circ} \mathrm{C}\right)$, in moderate respiratory distress, and had oxyhemoglobin desaturation of $94 \%$ on room air. CT imaging of the chest on admission revealed multiple bilateral ground-glass opacities, predominantly in subpleural areas of lower and middle regions of both lungs. Reticular changes were also seen in the same zones (Figure 1).

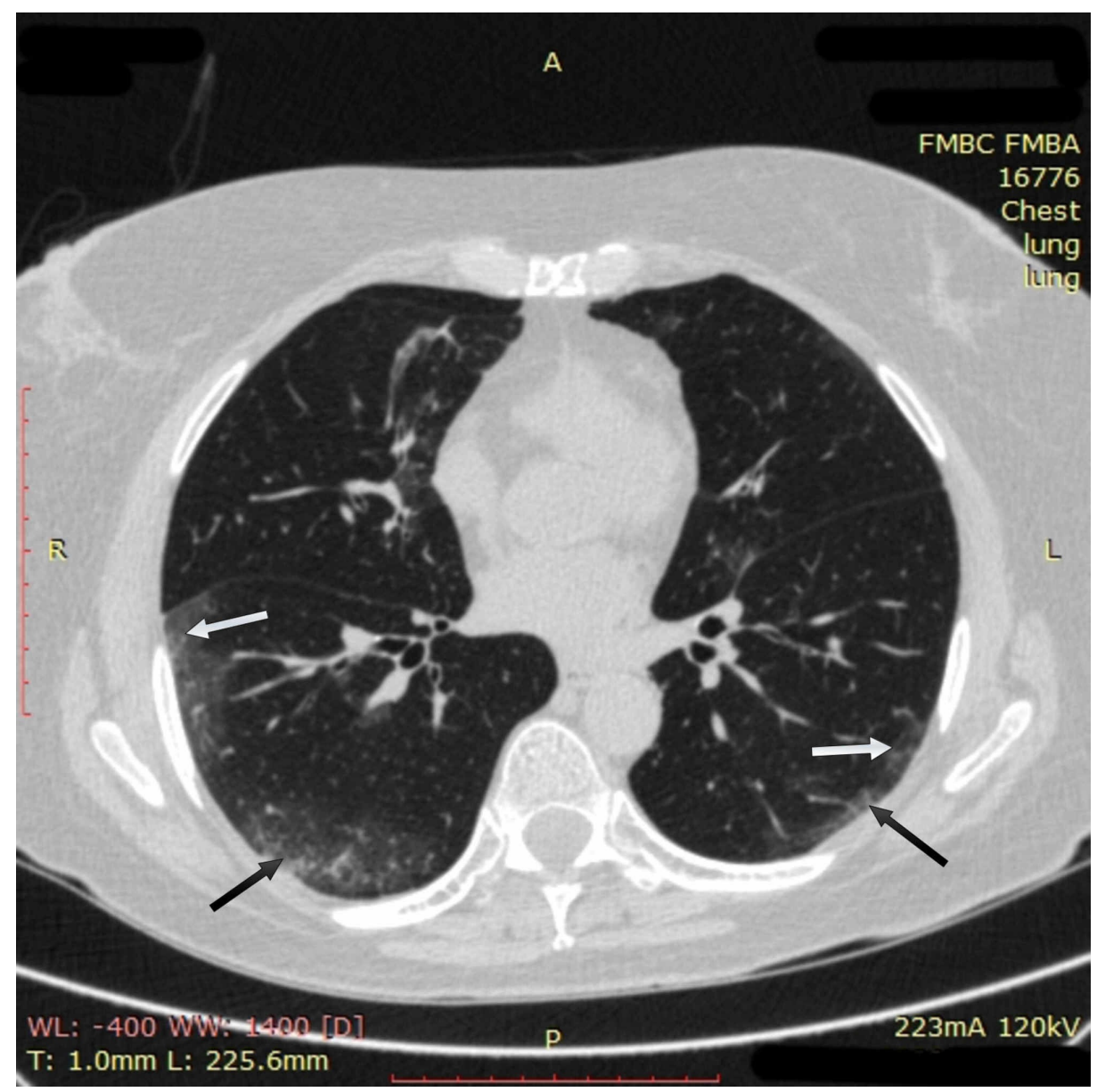

\section{FIGURE 1: Chest CT imaging of patient 1 on admission}

CT imaging on admission showed multiple bilateral ground-glass opacities (white arrows) in subpleural areas of lower and middle regions of both lungs; reticular changes in the same zones were also observed (black arrows)

CT: computed tomography

Laboratory tests were mostly normal except for a moderate C-reactive protein (CRP) increase (11.58 mg/L). Procalcitonin level on admission was normal $(<0.5 \mathrm{ng} / \mathrm{ml})$ (Table 1$)$. 


\section{Cureus}

\begin{tabular}{|c|c|c|c|c|c|c|c|}
\hline Laboratory parameter & Units & Reference range & On admission & Day 11 & Day 14 & Day 17 & Day 22 \\
\hline WBC & $\times 10^{9} / \mathrm{L}$ & $4.0-9.0$ & 5.7 & 9.3 & 10.1 & 12.2 & 10.9 \\
\hline Neutrophils (absolute) & $\times 10^{9} / \mathrm{L}$ & $1.7-7.7$ & 3.8 & 7.2 & 8.3 & 11.3 & 8.5 \\
\hline Lymphocytes (absolute) & $\times 10^{9} / \mathrm{L}$ & $0.4-4.4$ & 1.5 & 1.5 & 1.1 & 0.8 & 2.0 \\
\hline Hemoglobin & $g / L$ & $130-170$ & 135 & 117 & 115 & 120 & 112 \\
\hline Platelets & $\times 10^{9} / \mathrm{L}$ & $120-380$ & 198 & 408 & 426 & 421 & 231 \\
\hline ALT & $U / L$ & $5-33$ & 15 & 20 & 53 & 45 & 22 \\
\hline AST & $U / L$ & $5-32$ & 23 & 26 & 68 & 61 & 53 \\
\hline Total bilirubin & $\mathrm{mmol} / \mathrm{L}$ & $5.0-21.0$ & 6.0 & - & 9.0 & 12.0 & 4.0 \\
\hline Creatinine & $\mathrm{mmol} / \mathrm{L}$ & $44-80$ & 61 & 46 & 51 & 49 & 38 \\
\hline Glucose & $\mathrm{mmol} / \mathrm{L}$ & $3.9-6.0$ & 4.8 & 5.0 & 7.1 & 7.7 & 5.6 \\
\hline Sodium & $\mathrm{mmol} / \mathrm{L}$ & $136-145$ & 142 & 142 & 143 & 147 & 143 \\
\hline Potassium & $\mathrm{mmol} / \mathrm{L}$ & $3.5-5.1$ & 4.3 & 3.7 & 3.56 & 3.2 & 3.9 \\
\hline D-dimer & $\mathrm{mg} / \mathrm{L}$ & $0.00-0.55$ & - & 1.77 & - & 1.52 & - \\
\hline CRP & $\mathrm{mg} / \mathrm{L}$ & $0.00-5.00$ & 11.58 & 52.63 & 54.15 & 7.91 & 1.47 \\
\hline Procalcitonin & $\mathrm{ng} / \mathrm{mL}$ & $0.00-0.50$ & $<0.5$ & 0.05 & $<0.05$ & 0.08 & 0.03 \\
\hline SARS-CoV-2 RNA & Positive, negative & Negative & Positive & - & - & Positive & Negative \\
\hline
\end{tabular}

\section{TABLE 1: Laboratory results of patient 1}

WBC: white blood cell count; AST: aspartate aminotransferase (serum glutamic-oxaloacetic transaminase); ALT: alanine aminotransferase (serum glutamic pyruvic transaminase); SARS-CoV-2: severe acute respiratory syndrome coronavirus 2; CRP: C-reactive protein; RNA: ribonucleic acid

Based on typical symptoms, CT changes in the lungs, and a positive swab test for severe acute respiratory syndrome coronavirus 2 (SARS-CoV-2), the patient was diagnosed with a severe form of COVID-19 complicated with bilateral multilobar pneumonia and acute respiratory failure. The patient was started on clarithromycin 1,000 mg/day orally (PO) and hydroxychloroquine $800 \mathrm{mg}$ PO on the first day followed by a dose reduction to $400 \mathrm{mg}$ daily from the second day, ceftriaxone $2,000 \mathrm{mg} /$ day $\mathrm{IV}$, and tilorone $125 \mathrm{mg}$ PO daily for antiviral treatment. Oxygen supplementation via a facial mask $(5 \mathrm{~L} / \mathrm{min})$ was initiated leading to an increase in oxygen saturation $\left(\mathrm{SpO}_{2}\right)$ level in the patient to $96 \%$ with improvement in respiratory discomfort.

On April 9, 2020 (day four of hospitalization), the patient's condition began to deteriorate with increasing dyspnea and progressive fall in $\mathrm{SpO}_{2}$ from $93 \%$ on day four to $90 \%$ by day 11 despite noninvasive low-flow oxygenation of $5 \mathrm{~L} / \mathrm{min}$ via facial mask. The patient was switched to an alternative treatment including antiviral agents lopinavir $800 \mathrm{mg}$ PO daily, ritonavir $200 \mathrm{mg}$ PO daily, and umifenovir $400 \mathrm{mg}$ PO daily. Antimicrobial therapy was replaced with meropenem 3,000 mg IV daily.

Despite the measures taken, no positive change in the patient was observed by day 11 . Chest CT on day 11 showed multiple bilateral ground-glass opacities with new obfuscation zones in subpleural and central regions of the middle and upper right lobes with a noticeable reticular pattern. The density of previously seen opacities increased, and subpleural areas of consolidation appeared in the left lung (Figure 2). Overall involvement of pulmonary tissue reached $75 \%$ in the right lung and $30-50 \%$ in the left one. 


\section{Cureus}

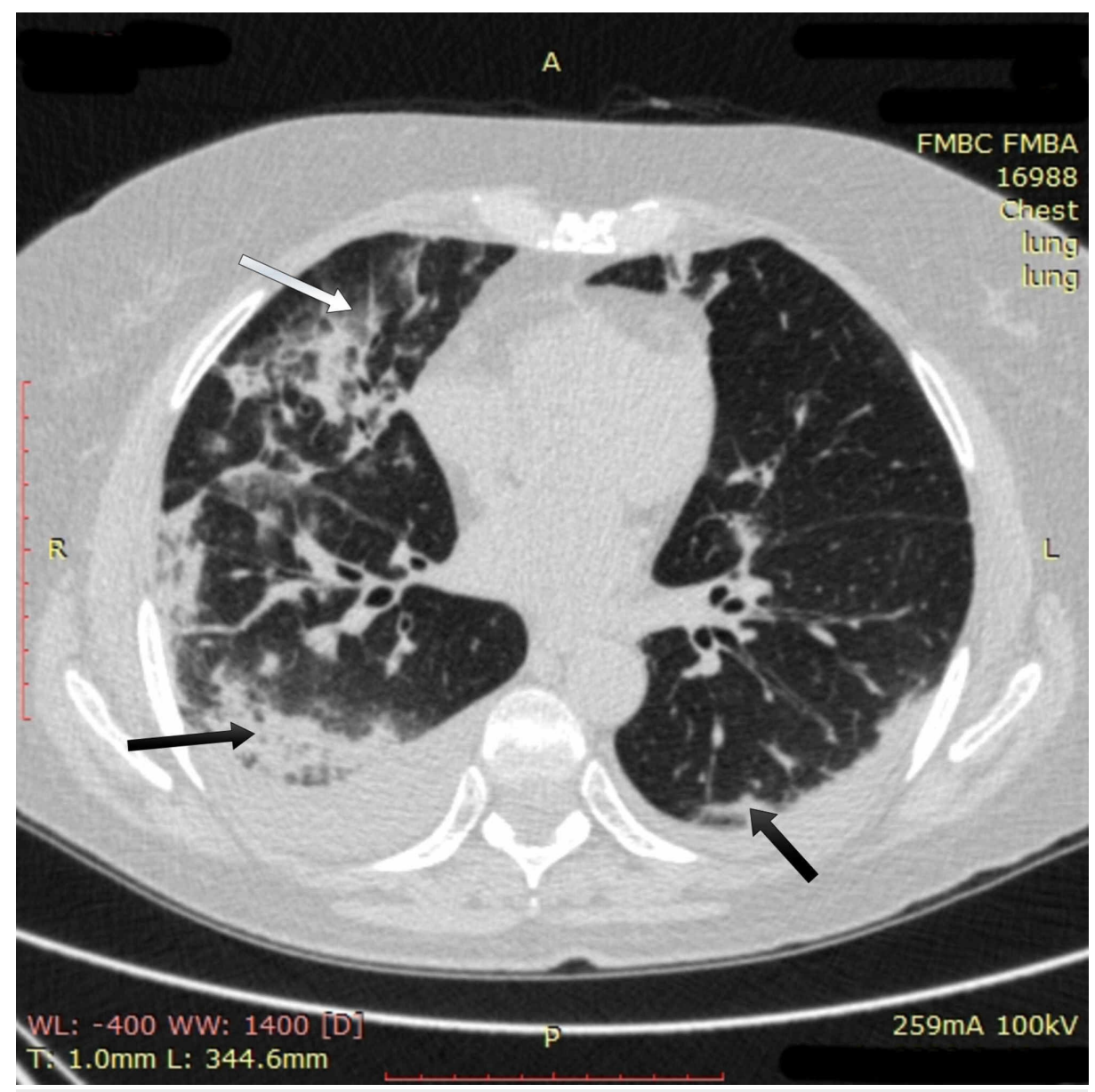

FIGURE 2: Chest CT imaging of patient 1 on day 11

Chest CT on day 11 showed multiple bilateral ground-glass opacities in subpleural and central regions of the middle and upper right lobes with a noticeable reticular pattern (white arrow); subpleural areas of consolidation in both lungs (black arrows) were also seen

CT: computed tomography

Laboratory data showed a high level of CRP $(52.63 \mathrm{mg} / \mathrm{L})$ and an increased concentration of D-dimer $(1.77$ $\mathrm{mg} / \mathrm{L}$ ). Body temperature and procalcitonin level were normal. Considering a high risk of progression to severe respiratory failure and intubation, a moderate dose of methylprednisolone (125 mg daily IV) was prescribed to the patient and given on days 11-14. Antimicrobial therapy with meropenem was continued.

Despite this, after temporary stabilization, the patient's condition continued to worsen. On day $14, \mathrm{SpO}_{2}$ decreased to $86 \%$ on low-flow oxygenation of $5 \mathrm{~L} / \mathrm{min}$ via facial mask in a prone position. The patient was fully conscious but suffered from pronounced dyspnea and fatigue. Chest X-ray on day 14 showed diffuse round multiple opacities without definite borders all over the lungs with a tendency to merge. Opacification involved more than $75 \%$ of the right lung and at least $50 \%$ of the left lung tissue. Laboratory data showed the same changes as on day 11.

Because of her progressive respiratory failure, the patient was transferred to the medical intensive care unit (ICU), where she was started on high-flow oxygen therapy of $45 \mathrm{~L} / \mathrm{min} \mathrm{FiO} 290 \%$ via nasal cannula. This raised $\mathrm{SpO}_{2}$ to $90-93 \%$ with blood oxygen saturation dropping back to $80 \%$ on room air. The patient was given a humanized anti-IL-6 receptor antibody, tocilizumab, (400 mg IV) once on day 14 . On days 14 and 15 , the condition of the patient remained extremely severe, without any improvement. Hypoxemia with $\mathrm{SpO}_{2}$ of $88-90 \%$ persisted despite high-flow oxygenation of up to $50 \mathrm{~L} / \mathrm{min}^{\mathrm{FiO}}{ }_{2} 100 \%$ and prone-positioning of the patient.

Considering the severe, life-threatening course of COVID-19 in a high-risk person, the lack of sufficient clinical response to tocilizumab, and an emerging perspective of intubation with subsequent fatality risk of more than $90 \%$ [2], the multidisciplinary team decided to prescribe a pulse therapy with methylprednisolone $(1,000 \mathrm{mg} /$ day IV for three consecutive days) to the patient as a potentially life-saving compassion 


\section{Cureus}

treatment. Pulse therapy with methylprednisolone was accompanied by IV immunoglobulin $20 \mathrm{~g} / \mathrm{day}$ for three consecutive days to prevent steroid-induced immunodeficiency and for its own immunomodulatory effect. This treatment was conducted on hospital days 15-17.

On the evening of day $15, \mathrm{SpO}_{2}$ stabilized in the patient at $95-96 \%$ on decreased high-flow oxygen of 10 $\mathrm{L} / \mathrm{min} \mathrm{FiO}_{2} 50 \%$ with a respiratory rate of $14-15$ breaths per minute. On day $16, \mathrm{SpO}_{2}$ reached $99 \%$ on highflow oxygenation of $10 \mathrm{~L} / \mathrm{min}$. On day 17, high-flow oxygenation was discontinued, and the patient sustained $\mathrm{SpO}_{2}$ at $95-97 \%$ on low-flow oxygenation of $5 \mathrm{~L} / \mathrm{min}$ via facial mask. Chest CT imaging on day 17 showed multidirectional changes. Multiple confluent ground-glass opacities increased in size. However, initial positive change was also found: bilateral pulmonary infiltrates had lost their density to the degree of ground-glass opacity and their area had decreased (Figure 3).

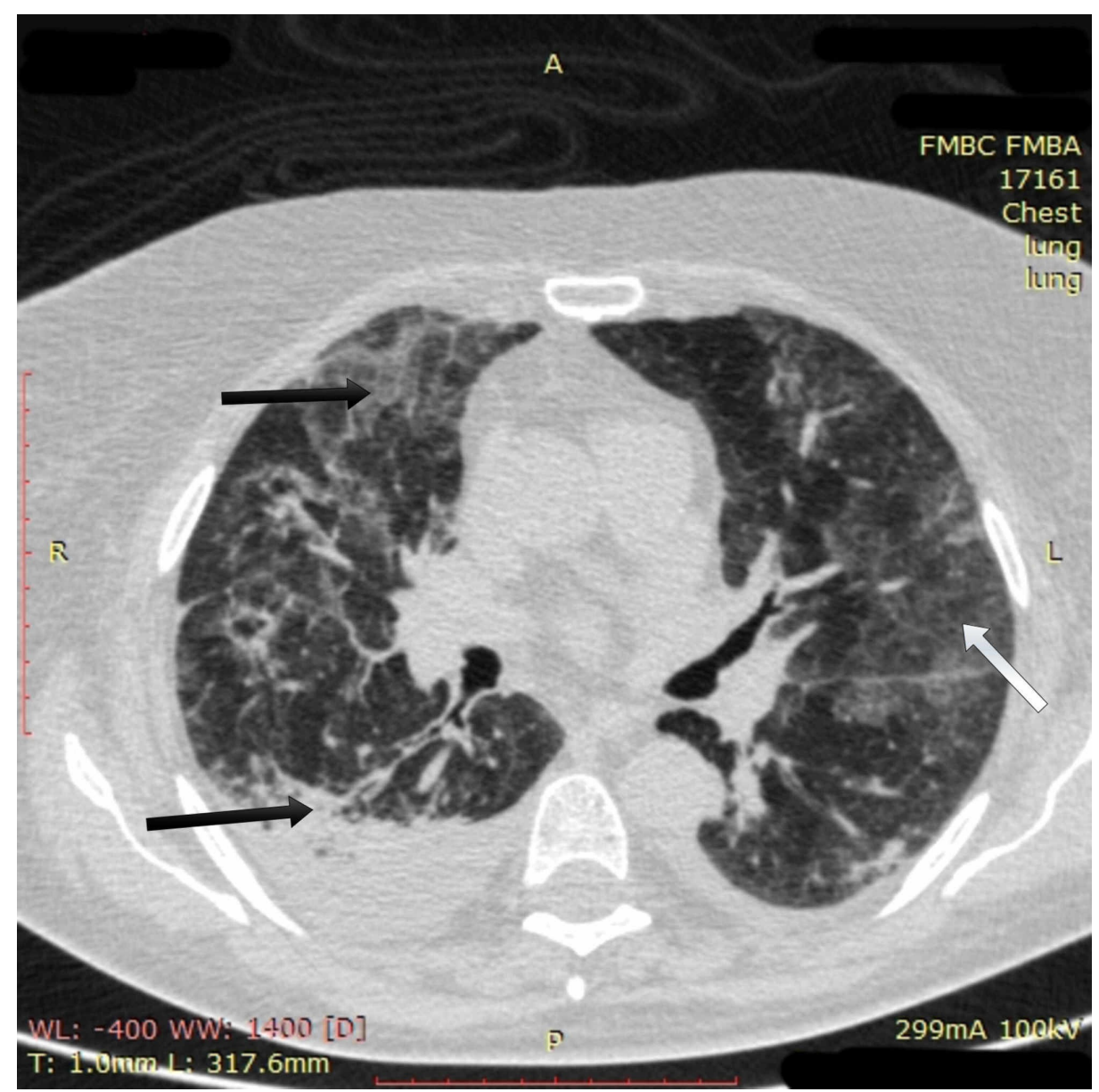

\section{FIGURE 3: Chest CT imaging of patient 1 on day 17}

Chest CT on day 17 showed multiple confluent ground-glass opacities had increased in size (white arrow); bilateral pulmonary infiltrates had lost their density to the degree of ground-glass opacity, and their area had decreased (black arrows)

CT: computed tomography

Further positive changes were seen on CT images on day 22: opacification in the left lung mostly resolved, and the area and density of obfuscation in the right lung had clearly decreased (Figure 4). 


\section{Cureus}

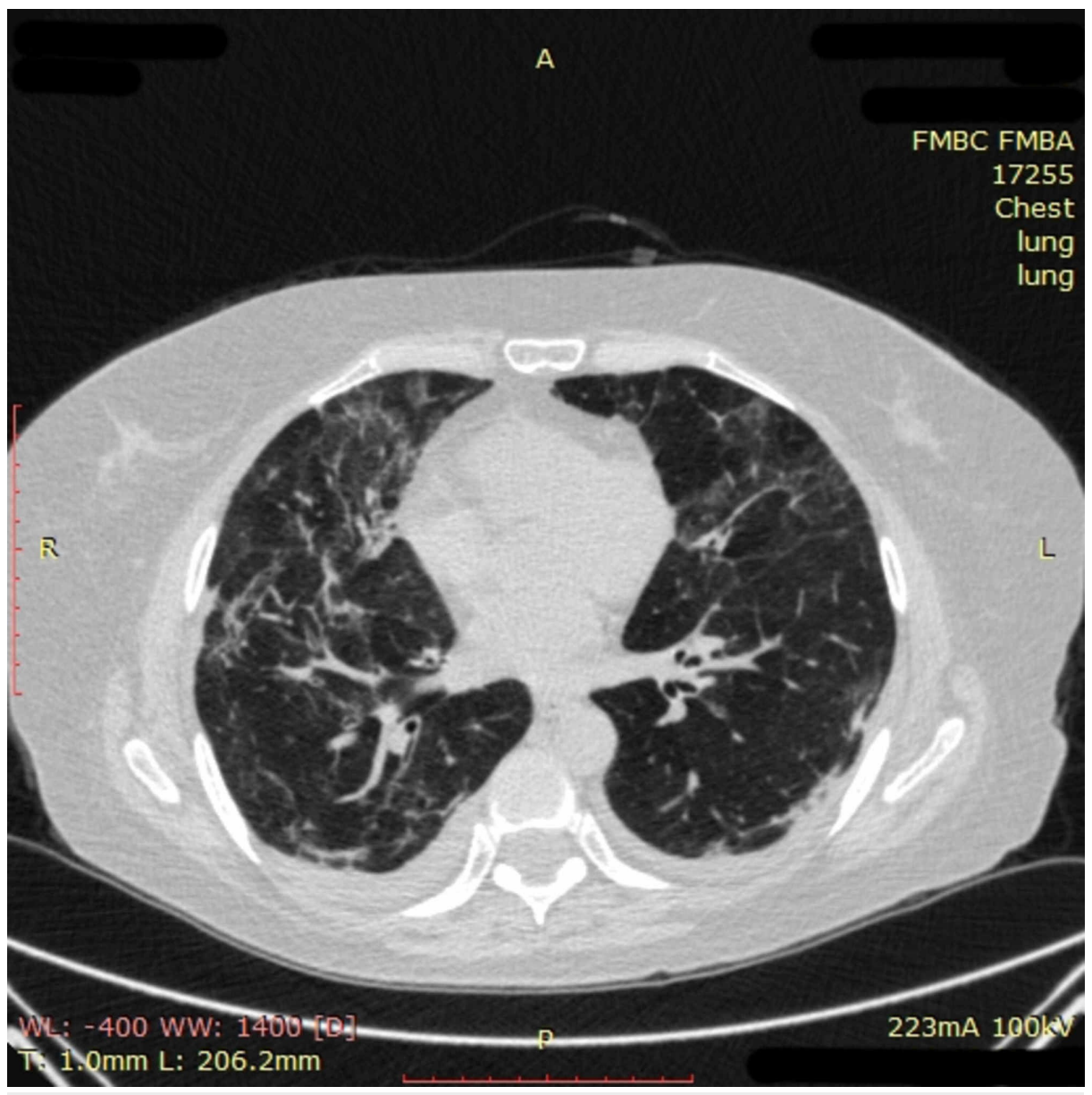

FIGURE 4: Chest CT imaging of patient 1 on day 22

Chest CT on day 22 showed that opacification in the left lung had mostly resolved, and the area and density of obfuscation in the right lung had clearly decreased

CT: computed tomography

During the following days, the clinical condition of the patient continued to improve. Respiratory failure resolved, and the patient was able to sustain normal (97-98\%) blood oxygen saturation on room air by day 25. Respiratory rate, blood pressure, and heart rate also returned to normal values. Respiratory symptoms decreased, leaving a small degree of dyspnea and fatigue. The first SARS-CoV-2-negative nasopharyngeal swab was obtained on day 20 and confirmed two days later. The patient was declared to be cured and discharged from the hospital on May 5, 2020 (hospital day 30).

\section{Case 2}

On April 20, 2020, a 60 -year-old woman with obesity and a history of chronic pancreatitis presented with five days of fever, dry cough, and weakness. On examination, she was febrile with $38.8^{\circ} \mathrm{C}$, not in respiratory distress, and her peripheral $\mathrm{SpO}_{2}$ was $95 \%$ on room air. A CT scan of the lungs on admission revealed multiple bilateral ground-glass opacities (Figure 5). 


\section{Cureus}

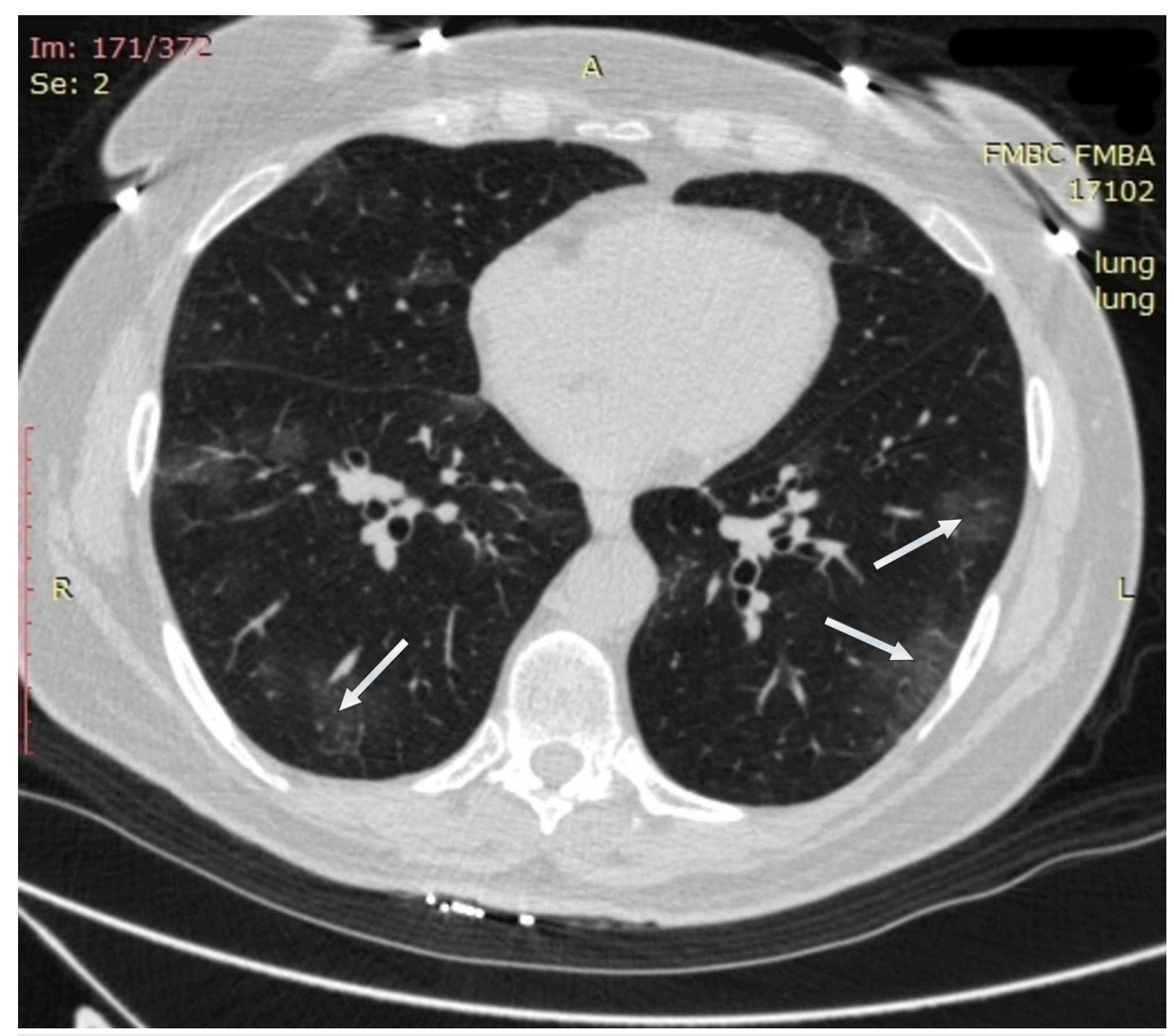

FIGURE 5: Chest CT imaging of patient 2 on admission

Chest CT imaging on admission revealed multiple ground-glass opacities of up to $3 \mathrm{~cm}$ in size (white arrows) in the majority of segments of both lungs, predominantly in the lower and middle regions, affecting less than $50 \%$ of the lung parenchyma

CT: computed tomography

COVID-19 was confirmed by a positive polymerase chain reaction (PCR) test obtained via a nasopharyngeal swab, and she was started on hydroxychloroquine, clarithromycin, ceftriaxone, and tilorone.

On day three, the patient's condition deteriorated with the appearance of dyspnea at rest and aggravation of fever and chills. Oxyhemoglobin saturation decreased to $87-91 \%$ on room air, requiring noninvasive lowflow oxygenation via facial mask. A CT scan on day three revealed large subpleural ground-glass opacities affecting up to 50\% of the lung parenchyma. Laboratory tests demonstrated a high level of CRP and ferritin (Table 2). 


\section{Cureus}

\begin{tabular}{|c|c|c|c|c|c|c|c|}
\hline Laboratory parameter & Units & Reference range & On admission & Day 3 & Day 8 & Day 10 & Day 21 \\
\hline WBC & $\times 10^{9} / \mathrm{L}$ & $4.0-9.0$ & 3.3 & 4.3 & 8.6 & 4.8 & 4.0 \\
\hline Neutrophils (absolute) & $\times 10^{9} / L$ & $1.7-7.7$ & 1.7 & 3.1 & 7.7 & 3.5 & 2.3 \\
\hline Lymphocytes (absolute) & $\times 10^{9} / \mathrm{L}$ & $0.4-4.4$ & 1.1 & 0.9 & 0.8 & 1.2 & 1.4 \\
\hline Hemoglobin & $g / L$ & $130-170$ & 128 & 121 & 111 & 110 & 116 \\
\hline Platelets & $\times 10^{9} / L$ & $120-380$ & 176 & 163 & 279 & 305 & 271 \\
\hline ALT & $U / L$ & $5-33$ & 37 & 101 & 93 & 100 & 126 \\
\hline AST & $U / L$ & $5-32$ & 38 & 87 & 55 & 80 & 51 \\
\hline Total bilirubin & $\mathrm{mmol} / \mathrm{L}$ & $5.0-21.0$ & 4.0 & 4.0 & 7.0 & 7.0 & 8.9 \\
\hline Creatinıne & $\mathrm{mmol} / \mathrm{L}$ & $44-80$ & 48 & 50 & 43 & 45 & 48 \\
\hline Glucose & $\mathrm{mmol} / \mathrm{L}$ & $3.9-6.0$ & 6.0 & 7.1 & 7.5 & 9.0 & 5.9 \\
\hline Sodium & $\mathrm{mmol} / \mathrm{L}$ & 136-145 & 141 & - & 140 & 136 & 142 \\
\hline Potassium & $\mathrm{mmol} / \mathrm{L}$ & $3.5-5.1$ & 4.2 & - & 3.4 & 3.2 & 3.8 \\
\hline D-dimer & $\mathrm{mg} / \mathrm{L}$ & $0.00-0.55$ & 1.36 & 0.75 & 0.92 & 1.54 & 0.42 \\
\hline CRP & $\mathrm{mg} / \mathrm{L}$ & $0.00-5.00$ & 7.52 & 34.77 & 17.34 & 5.80 & 0.69 \\
\hline Procalcitonin & $\mathrm{ng} / \mathrm{mL}$ & $0.00-0.50$ & 0.05 & 0.04 & 0.02 & $<0.5$ & - \\
\hline Ferritin & $\mathrm{ng} / \mathrm{mL}$ & $28-365$ & - & 868 & 797 & - & - \\
\hline SARS-CoV-2 RNA & Positive, negative & Negative & Positive & Positive & Positive & Positive & Negative \\
\hline
\end{tabular}

\section{TABLE 2: Laboratory results of patient 2}

WBC: white blood cell count; AST: aspartate aminotransferase (serum glutamic-oxaloacetic transaminase); ALT: alanine aminotransferase (serum glutamic pyruvic transaminase); SARS-CoV-2: severe acute respiratory syndrome coronavirus 2; CRP: C-reactive protein; RNA: ribonucleic acid

Considering the progression of the disease and significantly elevated markers of inflammation, the patient was diagnosed with CRS. A moderate dose of corticosteroids (methylprednisolone $125 \mathrm{mg} / \mathrm{day}$ IV) and enoxaparin $40 \mathrm{mg}$ subcutaneously twice daily were added to her therapy. During the next four days, the condition of the patient improved; her temperature decreased to $37.2^{\circ} \mathrm{C}$ and she was no longer in respiratory distress.

However, on day seven, the patient developed fever up to $39.3^{\circ} \mathrm{C}$ and a fall in $\mathrm{SpO}_{2}$ to $88 \%$ on low-flow oxygenation of $5 \mathrm{~L} / \mathrm{min}$ via facial mask. The patient was transferred to the medical ICU where she was started on high-flow oxygenation of $40 \mathrm{~L} / \mathrm{min} \mathrm{FiO} 250 \%$ via nasal cannula. The patient was also given tocilizumab ( $400 \mathrm{mg} \mathrm{IV}$ ). However, for the next three days, she continued to experience persistent fever, pronounced dyspnea, and fatigue. It was not possible to raise her $\mathrm{SpO}_{2}$ above $94 \%$, and high-flow oxygen of up to $50 \mathrm{~L} / \mathrm{min} \mathrm{FiO}_{2} 50 \%$ was required to reach this. On day eight, a CT scan revealed a further increase of subpleural ground-glass opacities (Figure ๑). 


\section{Cureus}

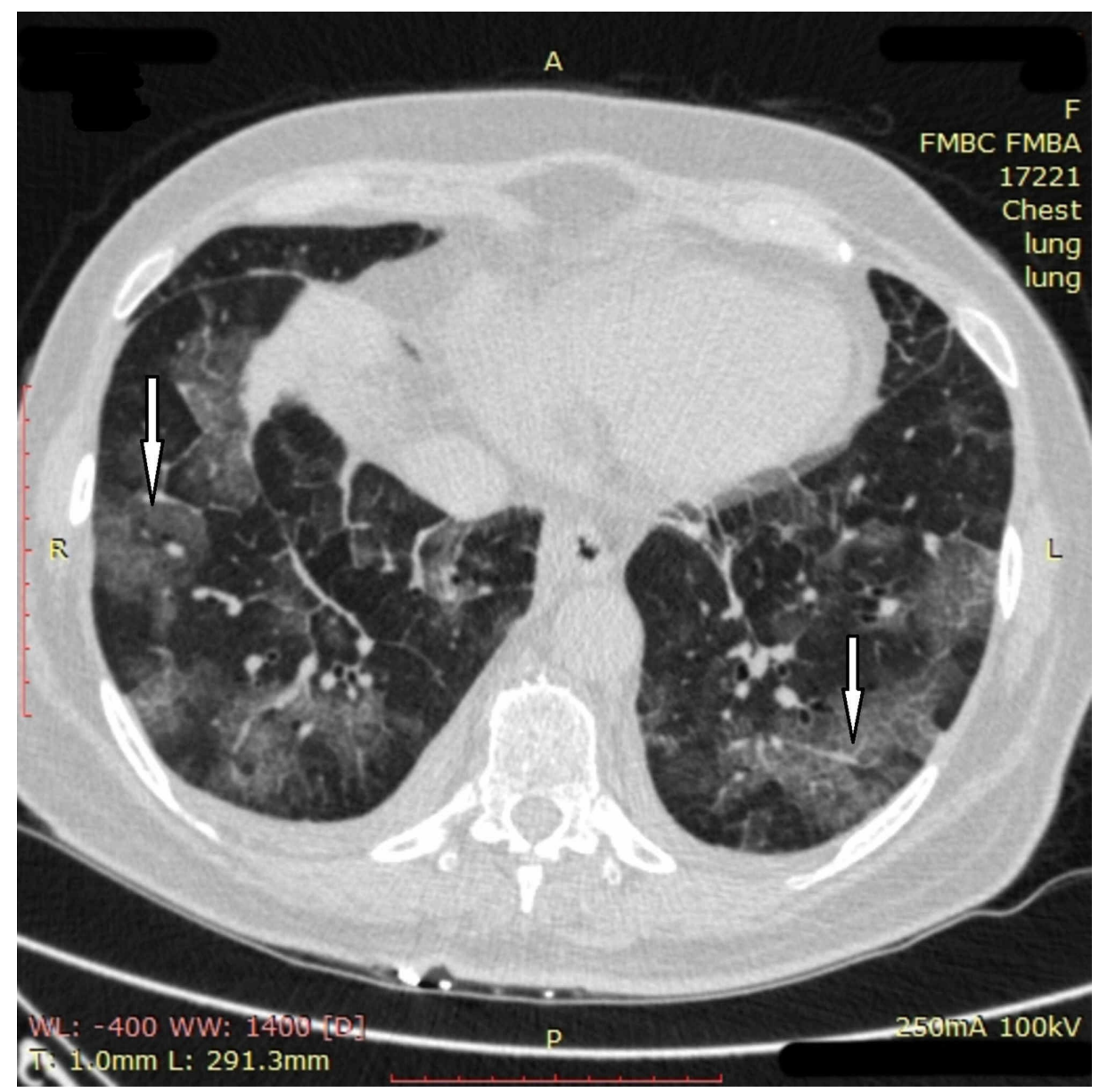

FIGURE 6: Chest CT imaging of patient 2 on day eight

CT scan on day eight revealed an increase of pre-existing opacities in size and density. New ground-glass opacities appeared in upper and lower zones of the lungs merging into large subpleural opacification areas (white arrows). In the left lung, small foci of consolidation were seen. Interlobular septal thickening could be noted in various parts of the lungs. Overall, pathological changes involved at least $75 \%$ of pulmonary tissue

CT: computed tomography

Laboratory data showed a high ferritin level and a moderate elevation of CRP, D-dimer, and aminotransferases. Because of the severe, life-threatening course of COVID-19 and insufficient effectiveness of previous treatment, the patient was given a pulse therapy with methylprednisolone (1,000 $\mathrm{mg} /$ day IV for three consecutive days) accompanied by IV immunoglobulin ( $20 \mathrm{~g} /$ day). This treatment was conducted on days 10-12. After that, the patient's condition improved significantly. Her body temperature and $\mathrm{SpO}_{2}$ normalized; high-flow oxygenation was discontinued, and the patient only had moderate residual weakness and dyspnea. On day 13, she returned to the regular ward and was discharged in good clinical condition on day 23 with two negative swab tests for SARS-CoV-2. Chest CT at discharge showed partial or complete resolution of ground-glass opacities in both lungs. A portion of opacities in all segments had turned into consolidation with no signs of pulmonary infection (Figure 7). 


\section{Cureus}

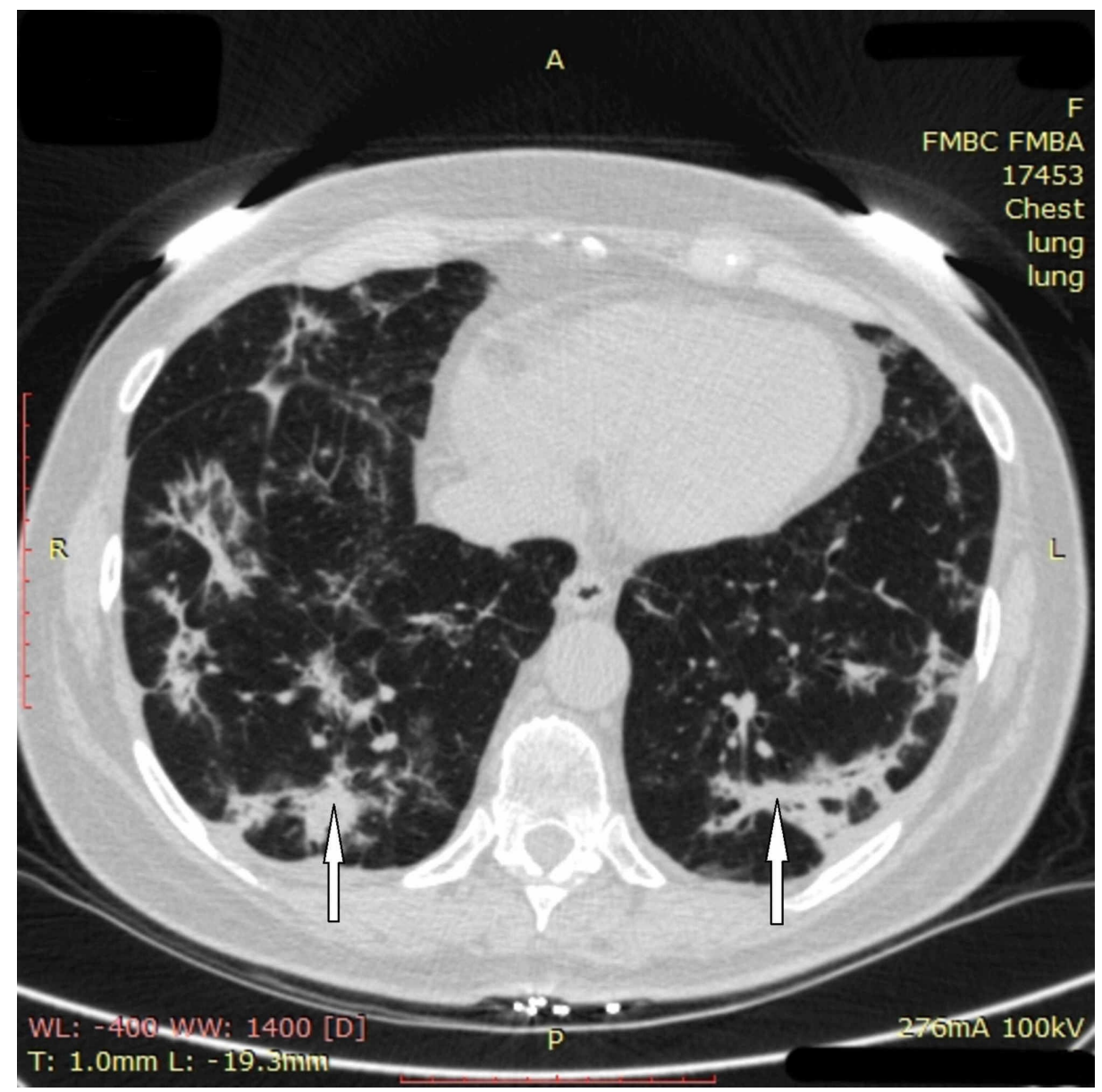

FIGURE 7: Chest CT imaging of patient 2 on day 13

Chest CT on day 13 showed partial or complete resolution of the opacities in both lungs with the amount of involved pulmonary tissue decreased to less than $50 \%$. A portion of opacities in all segments of the lungs had turned into consolidation (white arrows)

CT: computed tomography

\section{Case 3}

On April 21, 2020, a 33-year-old man with no medical history presented with seven days of fever, weakness, dyspnea on exertion, and loss of appetite. On examination, he was febrile with $38^{\circ} \mathrm{C}$, in moderate respiratory distress, and had mild oxyhemoglobin desaturation $\left(\mathrm{SpO}_{2}\right.$ of $94 \%$ on room air). Chest $\mathrm{CT}$ on admission revealed multiple ground-glass opacities and areas of pulmonary consolidation in all segments of the lungs (Figure 8). 


\section{Cureus}

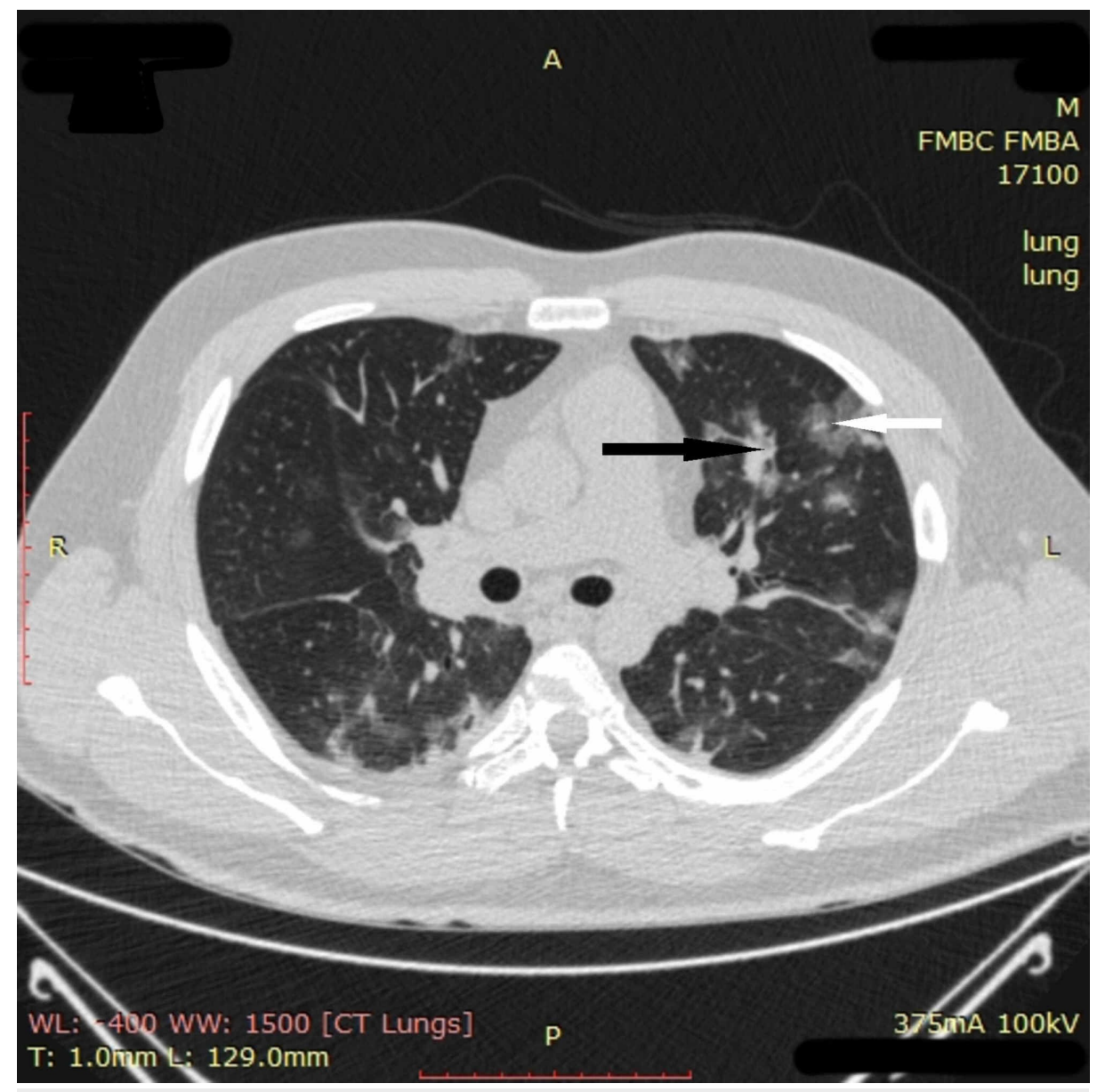

\section{FIGURE 8: Chest CT imaging of patient 3 on admission}

Chest CT on admission revealed multiple ground-glass opacities (white arrow) and areas of pulmonary consolidation (black arrow) in all segments of the lungs

CT: computed tomography

Blood tests demonstrated an extra-high level of ferritin and noticeably increased CRP and aminotransferases (Table 3). 


\begin{tabular}{|c|c|c|c|c|c|c|c|}
\hline Laboratory Parameter & Units & Reference range & On admission & Day 4 & Day 9 & Day 17 & Day 23 \\
\hline WBC & $\times 10^{9} / \mathrm{L}$ & $4.0-9.0$ & 9.7 & 9.9 & 34.7 & 5.9 & 5.1 \\
\hline Neutrophils (absolute) & $\times 10^{9} / L$ & $1.7-7.7$ & 7.80 & 8.40 & 33.20 & 3.90 & 2.80 \\
\hline Lymphocytes (absolute) & $\times 10^{9} / \mathrm{L}$ & $0.4-4.4$ & 1.50 & 1.30 & 1.20 & 1.50 & 2.0 \\
\hline Hemoglobin & $g / L$ & $130-170$ & 154 & 145 & 114 & 117 & 138 \\
\hline Platelets & $\times 10^{9} / L$ & $120-380$ & 206 & 230 & 331 & 223 & 250 \\
\hline ALT & $U / L$ & $5-33$ & 124 & 160 & 61 & 65 & 54 \\
\hline AST & $U / L$ & $5-32$ & 161 & 156 & 57 & 31 & 30 \\
\hline Total bilirubin & $\mathrm{mmol} / \mathrm{L}$ & $5.0-21.0$ & 4.0 & 8.0 & 11.0 & 7.0 & 13.5 \\
\hline Creatinıne & $\mathrm{mmol} / \mathrm{L}$ & $44-80$ & 85 & 86 & 122 & 71 & 87 \\
\hline Glucose & $\mathrm{mmol} / \mathrm{L}$ & $3.9-6.0$ & 5.8 & 9.4 & 8.5 & 5.9 & 5.0 \\
\hline Sodium & $\mathrm{mmol} / \mathrm{L}$ & 136-145 & 142 & 141 & 136 & 140 & 141 \\
\hline Potassium & $\mathrm{mmol} / \mathrm{L}$ & $3.5-5.1$ & 4.2 & 4.0 & 4.6 & 4.5 & 4.3 \\
\hline D-dimer & $\mathrm{mg} / \mathrm{L}$ & $0.00-0.55$ & 1.41 & 0.49 & 1.34 & 1.29 & - \\
\hline CRP & $\mathrm{mg} / \mathrm{L}$ & $0.00-5.00$ & 44.64 & 2.85 & 119.67 & 8.25 & 2.08 \\
\hline Procalcitonin & $\mathrm{ng} / \mathrm{mL}$ & $0.00-0.50$ & 0.08 & $<0.50$ & $>2$ & $<0.50$ & $<0.50$ \\
\hline Ferritin & $\mathrm{ng} / \mathrm{mL}$ & $28-365$ & 2540 & 1140 & - & 644 & - \\
\hline SARS-CoV-2 RNA & Positive, negative & Negative & Positive & Positive & Positive & Positive & Negative \\
\hline
\end{tabular}

\section{TABLE 3: Laboratory results of patient 3}

WBC: white blood cell count; AST: aspartate aminotransferase (serum glutamic-oxaloacetic transaminase); ALT: alanine aminotransferase (serum glutamic pyruvic transaminase); SARS-CoV-2: severe acute respiratory syndrome coronavirus 2; CRP: C-reactive protein; RNA: ribonucleic acid

COVID-19 was confirmed by a positive PCR test obtained via a nasopharyngeal swab. Because of a pronounced pulmonary involvement on CT and clinical data suggestive of CRS, the patient was started on methylprednisolone $125 \mathrm{mg}$ IV daily, enoxaparin, lopinavir, ritonavir, umifenovir, and ceftriaxone. Despite treatment, during the first two hospital days, he experienced severe symptoms including transient elevations of body temperature to $38^{\circ} \mathrm{C}$ with chills, cough, shortness of breath, dizziness, and insomnia. Blood oxygen saturation decreased to $85-90 \%$ on room air, requiring noninvasive low-flow oxygenation with growth in $\mathrm{SpO}_{2}$ to $90-92 \%$ on $5 \mathrm{~L} / \mathrm{min}$ of oxygen via facial mask. The patient was fully conscious, complied with recommendations of the personnel, and was put to a prone-position for two hours every two hours.

On day three, he underwent a deterioration with severe dyspnea at rest, aggravation of fever $\left(38.1^{\circ} \mathrm{C}\right)$, and fall in $\mathrm{SpO}_{2}$ to $87 \%$ on low-flow oxygenation of $5 \mathrm{~L} / \mathrm{min}$ via facial mask. The patient was transferred to the medical ICU where he was started on high-flow oxygenation of $40 \mathrm{~L} / \mathrm{min} \mathrm{FiO}_{2} 50 \%$ via nasal cannula and given $400 \mathrm{mg}$ tocilizumab IV. By the end of day three, the body temperature decreased in the patient to 37.1 ${ }^{\circ} \mathrm{C}$. On high-flow oxygenation via nasal cannula, blood oxygen saturation fluctuated around $92 \%$ with rapid desaturation to $87 \%$ on room air; the respiratory rate was $22-24$ breaths per minute. The patient was hemodynamically stable with a blood pressure of $130 / 70 \mathrm{mmHg}$ and a heart rate of 94 beats per minute.

On day four, a threatening progression of respiratory insufficiency occurred. There was a registered a fall in $\mathrm{SpO}_{2}$ to $80 \%$ on high-flow oxygenation via nasal cannula; the patient became agitated, his respiratory rate increased to $42-44$ per minute, blood pressure reached $175 / 94 \mathrm{mmHg}$, and heart rate increased to 135 per minute. Arterial blood gas analysis revealed a pH of 7.33, $\mathrm{paO}_{2}$ of $59 \mathrm{mmHg}$, and $\mathrm{paCO}_{2}$ of $35.7 \mathrm{mmHg}$. The patient was intubated and treated with low tidal volume ventilation. This led to the stabilizing of his clinical condition. Blood oxygen saturation increased to $98 \%$, blood pressure decreased to 120/70 $\mathrm{mmHg}$, and heart rate was 85 per minute. CT scan on day four demonstrated multiple ground-glass opacities and areas of consolidation in all segments of the lungs (Figure 9). CT picture was suggestive of ARDS. 


\section{Cureus}

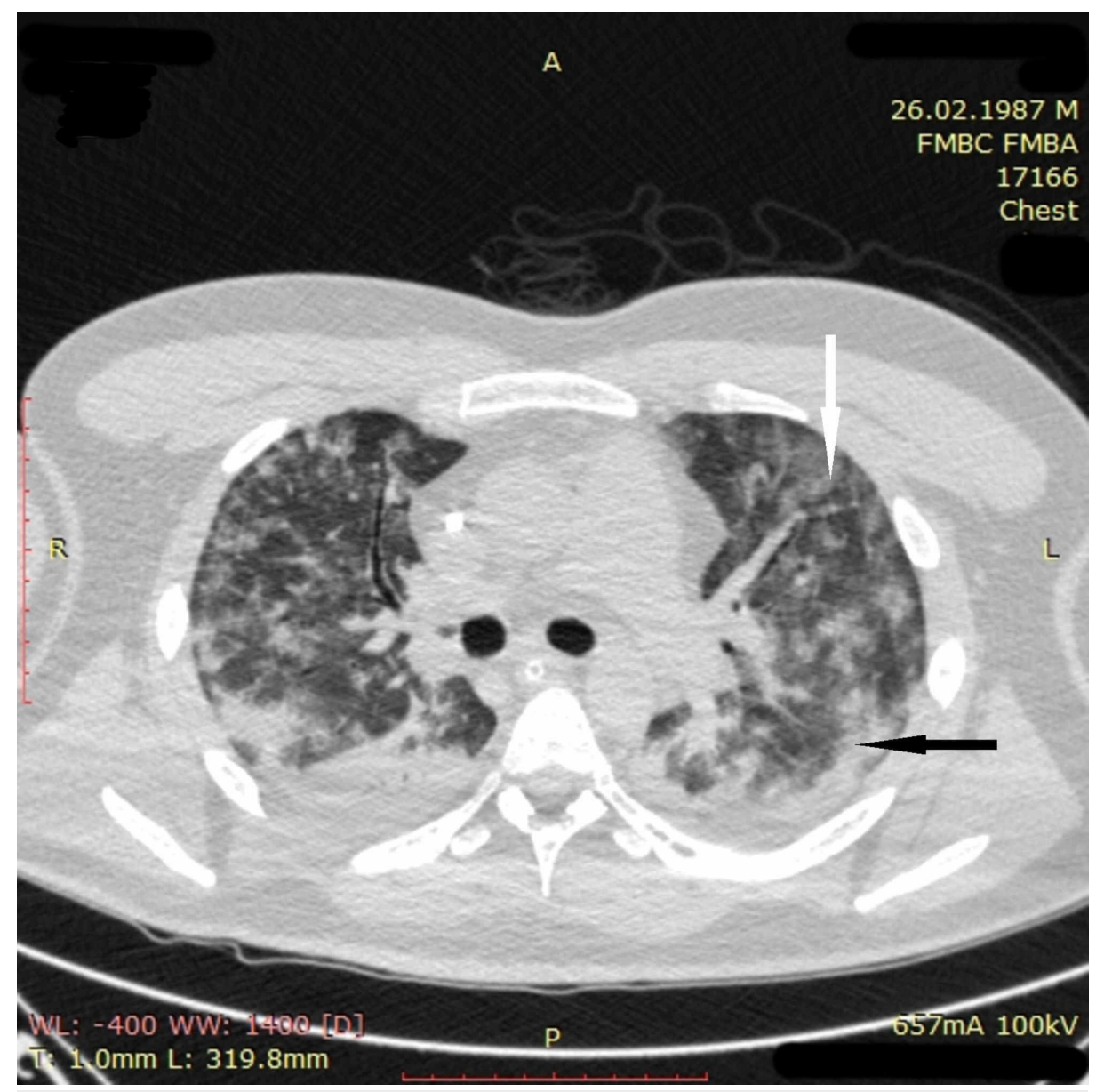

\section{FIGURE 9: Chest CT imaging of patient 3 on day four}

CT scan on day four demonstrated the appearance of multiple merging ground-glass opacities (white arrow) and areas of consolidation (black arrow) in all segments of the lungs. Partial atelectasis of both lower lobes was also noted. In general, pathological changes involved more than $75 \%$ of pulmonary tissue. CT picture was suggestive of ARDS

CT: computed tomography; ARDS: acute respiratory distress syndrome

Considering the risk of the unfavorable future course of the disease, the patient was prescribed a pulse therapy with methylprednisolone. On hospital days four to six, he received methylprednisolone 1,000 $\mathrm{mg} / \mathrm{day} \mathrm{IV}$, and his condition noticeably improved. On day six, sedation was discontinued, and the patient demonstrated $\mathrm{SpO}_{2}$ of $98 \%$ on spontaneous ventilation. He was fully conscious and responsive to non-verbal contact.

On day eight, the patient experienced transient deterioration with an elevation of body temperature to 40.1 ${ }^{\circ} \mathrm{C}, \mathrm{SpO}_{2}$ fall to $94 \%$, and septic shock requiring a norepinephrine drip. Chest $\mathrm{CT}$ on day nine showed a

distinct positive change in CT picture compared to that of day four. The ground-glass opacities decreased in amount and density all over the lungs. However, new pulmonary tissue consolidation was found in the lower lobe of the right lung, suggestive of pneumonia (Figure 10). 


\section{Cureus}

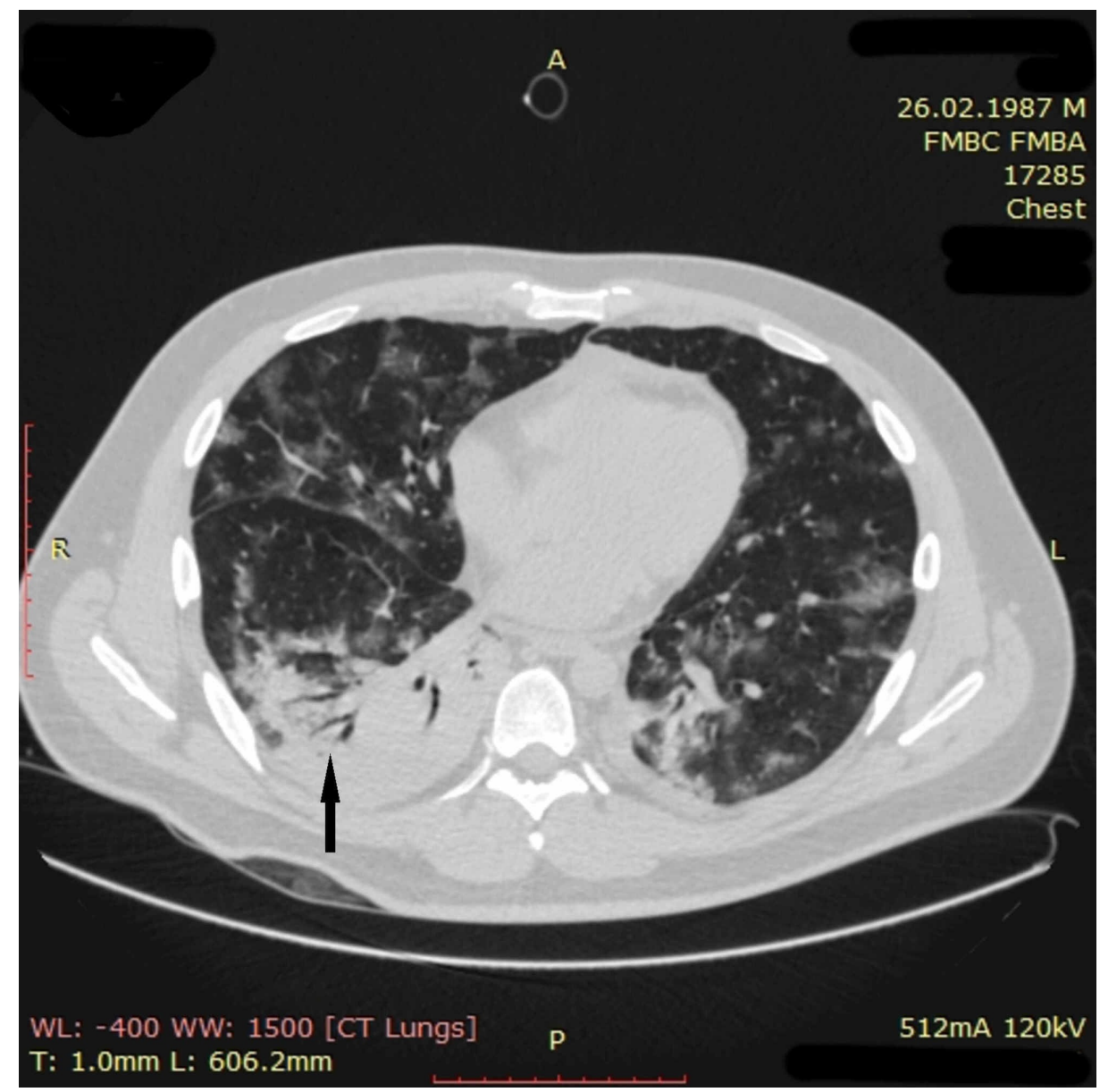

\section{FIGURE 10: Chest CT imaging of patient 3 on day nine}

Chest CT performed on day nine showed a distinct positive change in CT picture compared to that of day four. The ground-glass opacities noticeably decreased in amount and density all over the lungs. Pneumatized parenchyma could be seen again in all pulmonary segments. The total volume of affected lung tissue was down to approximately $50 \%$. However, a new zone of pulmonary tissue consolidation with a symptom of air bronchogram (black arrow) was found in the lower lobe of the right lung, suggestive of pneumonia

CT: computed tomography

Blood analysis on day nine revealed a pronounced neutrophil leukocytosis, mild normochromic anemia, further elevation of CRP, and a high level of procalcitonin. The patient was diagnosed with nosocomial pneumonia. After a seven-day course of meropenem and an infusion of IV immunoglobulin (20 g), his condition finally improved; he was weaned from the ventilator on day 14 and returned to the regular ward on day 16 with $\mathrm{SpO}_{2}$ of $99 \%$ on low-flow oxygen.

The patient was discharged home on day 23 with no symptoms, normal oxyhemoglobin saturation, and a negative nasopharyngeal swab test for SARS-CoV-2. Chest CT on discharge revealed partial resolution of pulmonary consolidation in the right lower lobe and a further decrease in size and density of ground-glass opacities all over the lungs (Figure 11). 


\section{Cureus}

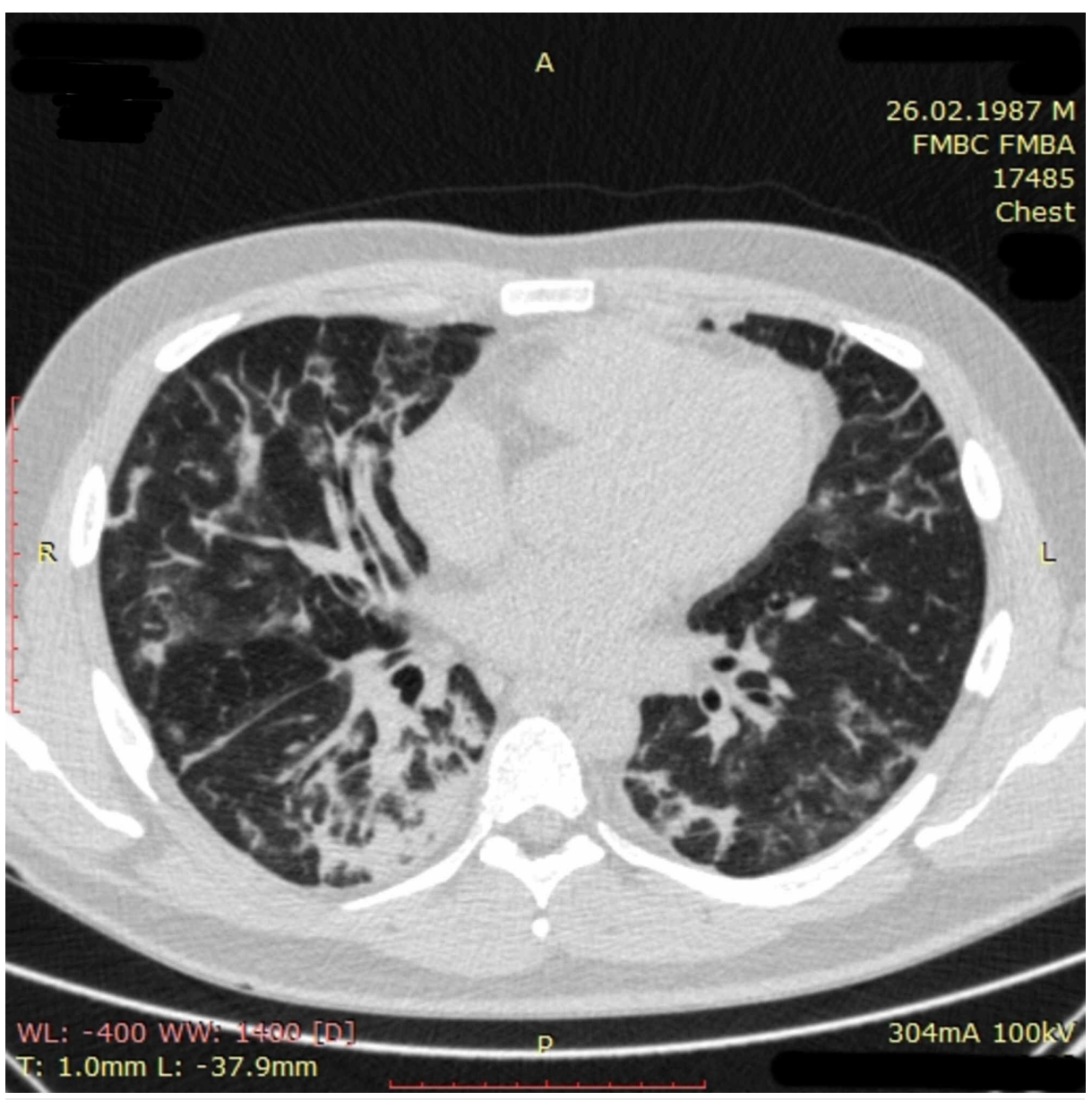

FIGURE 11: Chest CT imaging of patient 3 on day 23

Chest CT on day 23 revealed partial resolution of pulmonary tissue consolidation in the right lower lobe and a further decrease of size and density of ground-glass opacities all over the lungs

CT: computed tomography

\section{Discussion}

In this report, we described a cohort of three patients with severe, life-threatening COVID-19, who had failed to improve after consecutive administration of moderate doses of corticosteroids and specific IL-6 inhibitor tocilizumab, but demonstrated a favorable response to pulse therapy with high doses of methylprednisolone and IV human immunoglobulin.

In two of the patients, deterioration was associated with clinical features suggestive of hyperinflammation possibly due to CRS [high fever, (multi)organ failure, marked elevation of CRP, ferritin, D-dimer, and aminotransferases]. In one patient, vast pulmonary involvement and respiratory failure were accompanied by a relatively modest increase in the level of CRP and D-dimer. Considering the evidence relating to the immunopathological nature of COVID-19-associated severe pneumonia, a specific IL-6 inhibitor, tocilizumab, was selected to counter the rampant exacerbation in these patients. Unfortunately, tocilizumab did not produce a prompt clinical relief in this cohort.

Patients with severe COVID-19 usually have increased levels of multiple cytokines $[10,11]$. It can be assumed that the blockade of only one of them, namely IL-6, may not have enough power to suppress the development of such a threatening COVID-19 complication as CRS. To be fully effective in the treatment of CRS in COVID-19 patients, immunomodulating therapies are still awaited to suppress multiple proinflammatory cytokine pathways. And in such situations, corticosteroids along with IV immunoglobulin are usually used first [12]. Facing continued worsening of the condition of the described patients, the multidisciplinary group in charge of treatment decided to use pulse therapy with high doses of corticosteroids and IV immunoglobulin as ultima ratio before the obvious indications to intubation occur or immediately after intubation given the unpredictable outcome on mechanical ventilation. 
is necessary to obtain a prompt immunosuppressive effect [13-16]. To our knowledge, pulse therapy with corticosteroids had not been previously used for the treatment of severe lung impairment in COVID-19. And we have managed to find only one report about the successful use of IV immunoglobulin in patients with severe COVID-19 [17]. But we consider such therapy justified as both steroids and IV immunoglobulin are positioned as the first-line cure for CRS [12].

The result seemed overwhelmingly positive to us. During the first day of pulse therapy, the patients' blood oxygen saturation and hemodynamics stabilized, and body temperature decreased if elevated. Till the end of their three-day course, there was no need for high-flow oxygenation any more in two of the patients. The third patient, who was intubated prior to pulse therapy, was switched to spontaneous ventilation and was capable of sustaining a $98 \%$ blood oxygen saturation on this regimen. In all the patients, clinical improvement was accompanied by a rapid positive dynamic of the CT picture in the lungs. The patients were soon discharged in good clinical condition with negative swab tests for SARS-CoV-2. Of note, patients with a similar catastrophic course of the disease often die or need prolonged mechanical ventilation with unpredictable outcomes [2].

Pulse therapy with methylprednisolone and IV immunoglobulin was generally safe and well-tolerated. We did not observe any serious side effects in the described patients. There were noticeable fluctuations of glucose and electrolyte levels surrounding pulse therapy, but they were not critical and could be effectively managed in a hospital setting. Heart rhythm disturbances, uncontrolled hypertension, and gastrointestinal bleeding were not registered in connection with pulse therapy. The period of viral shedding amounted to 2023 days in the described patients. This correlates well with the data from other authors who found the average time to viral clearance in SARS-CoV-2 infection to be 20 (range: 17-24) days [2]. Hence, there was no evidence of protracted persistence of the virus in patients who received pulse therapy with high doses of methylprednisolone and IV immunoglobulin.

We used pulse therapy with methylprednisolone in combination with IV immunoglobulin in order to prevent infectious complications and based on immunoglobulin's own immunomodulating effect $[12,16,18]$. The effectiveness and safety of these components, either used separately or in combination, require further evaluation in randomized controlled studies.

\section{Conclusions}

Pulse therapy with high doses of methylprednisolone and IV immunoglobulin was associated with a prompt elimination of respiratory failure, improvement in the clinical manifestations of the CRS, and reversal of pulmonary CT changes in patients with severe COVID-19 regardless of the initial level of biomarkers of inflammation. Pulse therapy with methylprednisolone in combination with IV immunoglobulin was generally safe and well-tolerated. There was no evidence of protracted persistence of the virus in patients who received this treatment.

\section{Additional Information \\ Disclosures}

Human subjects: Consent was obtained by all participants in this study. Conflicts of interest: In compliance with the ICMJE uniform disclosure form, all authors declare the following: Payment/services info: All authors have declared that no financial support was received from any organization for the submitted work. Financial relationships: All authors have declared that they have no financial relationships at present or within the previous three years with any organizations that might have an interest in the submitted work. Other relationships: All authors have declared that there are no other relationships or activities that could appear to have influenced the submitted work.

\section{Acknowledgements}

The treatment plan for the patient was implemented in close collaboration with physicians from the departments of infectious diseases, radiology, anaesthesiology and critical care, and the Sports Medicine Centre of Federal Medical Biological Agency of Russia. The authors respectfully acknowledge the valuable contribution of Dmitrii A. Shikunov, MD; Aleksandra P. Netrebina, MD; Artem I. Kryntsilov, MD; and Aleksandr E. Ozerov, MD to the research, analysis, and interpretation of the data.

\section{References}

1. Wu Z, McGoogan JM: Characteristics of and important lessons from the coronavirus disease 2019 (COVID19) outbreak in China: summary of a report of 72314 cases from the Chinese Center for Disease Control and Prevention. JAMA. 2020, 13:1239-42. 10.1001/jama.2020.2648

2. Zhou F, Yu T, Du R, et al.: Clinical course and risk factors for mortality of adult inpatients with COVID-19 in Wuhan, China: a retrospective cohort study. Lancet. 2020, 395:1054-62. 10.1016/S0140-6736(20)30566-3

3. Thachil J: The versatile heparin in COVID-19. J Thromb Haemost. 2020, 18:1020-22. 10.1111/jth.14821

4. Rodriguez-Morales AJ, Cardona-Ospina JA, Gutiérrez-Ocampo E, et al.: Clinical, laboratory and imaging features of COVID-19: a systematic review and meta-analysis. Travel Med Infect Dis. 2020, 34:101623. 
5. Li D, Chen Y, Liu H, et al.: Immune dysfunction leads to mortality and organ injury in patients with COVID19 in China: insights from ERS-COVID-19 study. Signal Transduct Target Ther. 2020, 5:62. 10.1038/s41392020-0163-5

6. Prete M, Favoino E, Catacchio G, Racanelli V, Perosa F: SARS-CoV-2 inflammatory syndrome. Clinical features and rationale for immunological treatment. Int J Mol Sci. 2020, 21:3377. 10.3390/ijms21093377

7. Pontali E, Volpi S, Antonucci G, et al.: Safety and efficacy of early high-dose IV anakinra in severe COVID-19 lung disease. J Allergy Clin Immunol. 2020, 146:213-5. 10.1016/j.jaci.2020.05.002

8. van Kraaij TDA, Mostard RLM, Ramiro S, et al.: Tocilizumab in severe COVID-19 pneumonia and concomitant cytokine release syndrome. Eur J Case Rep Intern Med. 2020, 5:001675. 10.12890/2020_001675

9. Toniati P, Piva S, Cattalini M, et al.: Tocilizumab for the treatment of severe COVID-19 pneumonia with hyperinflammatory syndrome and acute respiratory failure: a single center study of 100 patients in Brescia, Italy. Autoimmun Rev. 2020, 19:102568. 10.1016/j.autrev.2020.102568

10. Chen G, Wu D, Guo W, et al.: Clinical and immunological features of severe and moderate coronavirus disease 2019. J Clin Invest. 2020, 130:2620-29. 10.1172/JCI137244

11. Picchianti Diamanti A, Rosado MM, Pioli C, Sesti G, Laganà B: Cytokine release syndrome in COVID-19 patients, a new scenario for an old concern: the fragile balance between infections and autoimmunity. Int J Mol Sci. 2020, 21:3330. 10.3390/ijms21093330

12. Henderson LA, Canna SW, Schulert GS, et al.: On the alert for cytokine storm: immunopathology in COVID19. Arthritis Rheumatol. 2020, 72:1059-63. 10.1002/art.41285

13. Rom E, Amarilyo G, Levinski Y, Bilavsky E, Goldberg O, Amir J, Harel L: Protracted febrile myalgia syndrome treated with pulse of corticosteroids. Semin Arthritis Rheum. 2018, 47:897-9. 10.1016/j.semarthrit.2017.10.008

14. Smets I, Van Deun L, Bohyn C, et al.: Corticosteroids in the management of acute multiple sclerosis exacerbations. Acta Neurol Belg. 2017, 117:623-33. 10.1007/s13760-017-0772-0

15. Zampeli E, Klinman DM, Gershwin ME, Moutsopoulos HM: A comprehensive evaluation for the treatment of lupus nephritis. J Autoimmun. 2017, 78:1-10. 10.1016/j.jaut.2016.12.011

16. Perez EE, Orange JS, Bonilla F, et al.: Update on the use of immunoglobulin in human disease: a review of evidence. J Allergy Clin Immunol. 2017, 139:S1-46. 10.1016/j.jaci.2016.09.023

17. Cao W, Liu X, Bai T, et al.: High-dose intravenous immunoglobulin as a therapeutic option for deteriorating patients with coronavirus disease 2019. Open Forum Infect Dis. 2020, 7:ofaa102. 10.1093/ofid/ofaa102

18. Chaigne B, Mouthon L: Mechanisms of action of intravenous immunoglobulin. Transfus Apher Sci. 2017, 56:45-9. 10.1016/j.transci.2016.12.017 